\title{
Ambient Air Pollution and Type 2 Diabetes Mellitus: A Systematic Review of Epidemiologic Research
}

\author{
Sung Kyun Park • Weiye Wang
}

Published online: 5 June 2014

(C) Springer International Publishing AG 2014

\begin{abstract}
Recent experimental and epidemiologic studies have suggested air pollution as a new risk factor for type 2 diabetes mellitus (T2DM). We conducted a systematic review of the epidemiologic studies on the association of air pollution with T2DM and related outcomes published by December 2013. We identified 22 studies: six prospective studies on incident T2DM; two prospective study on diabetes mortality; four cross-sectional studies on prevalent T2DM; seven ecological studies on mortality or morbidity from diabetes; and three studies on glucose or insulin levels. The evidence of the association between long-term exposure to fine particles $\left(\mathrm{PM}_{2.5}\right)$ and the risk of T2DM is suggestive. The summary hazard ratio of the association between long-term $\mathrm{PM}_{2.5}$ exposure and incident T2DM was $1.11(95 \%$ CI $1.03,1.19)$ for a $10 \mu \mathrm{g} / \mathrm{m}^{3}$ increase. The evidence on the association between long-term traffic-related exposure (measured by nitrogen dioxide or nitrogen oxides) and the risk of T2DM was also suggestive, although most studies were conducted in women. For short-term effects of air pollution on diabetes mortality or hospital/emergency admissions, we conclude that the evidence is not sufficient to infer a causal relationship. Because most studies were conducted in North America or in Europe where exposure levels are relatively low, more studies are needed in recently urbanized areas in Asia and Latin America where air pollution levels are much higher and $\mathrm{T} 2 \mathrm{DM}$ is an emerging public health concern.
\end{abstract}

Keywords Air pollution - Meta-analysis · Nitrogen dioxide Particulate matters · Systematic review · Type 2 diabetes

S. K. Park $(\bowtie) \cdot$ W. Wang

Departments of Epidemiology and Environmental Health Sciences,

University of Michigan School of Public Health, 1415 Washington

Heights, Ann Arbor, MI 48109, USA

e-mail: sungkyun@umich.edu

\section{Introduction}

Type 2 diabetes mellitus (T2DM) is a metabolic disorder characterized by high glucose levels in the blood caused by insulin resistance and relative insulin deficiency [1]. There are currently 347 million people with diabetes around the world and T2DM represents approximately $90 \%$ of people with diabetes [2]. High fasting blood glucose was ranked as the 7th risk factor for global disease burden and accounted for 3.4 million deaths and $3.6 \%$ of disability-adjusted life-years (DALYs) in 2010 [3]. While recent genome-wide association studies have uncovered genetic variants associated with T2DM risk [4, 5], these variants collectively account for only a small proportion of T2DM risk, suggesting a substantial role of modifiable risk factors in the development of T2DM. Although diet and physical activity are well-established risk factors for T2DM [6], there is growing evidence that environmental pollutants also play an important role in the pathogenesis of T2DM [7].

Air pollution has been suggested as a risk factor for T2DM. Recent reviews based on animal studies summarized potential biological mechanisms of air pollution-induced insulin resistance and T2DM [8, 9•], including particle-mediated alterations in glucose homeostasis, inflammation in visceral adipose tissue, endoplasmic reticulum (ER) stress in liver and lung, mitochondrial dysfunction and brown adipose tissue dysfunction, inflammation mediated through toll-like receptors and nucleotide oligomerization domain receptors, and inflammatory signaling in key regions of the hypothalamus. Epidemiologic studies of air pollution and T2DM have provided mixed results [10-22, 23•, 24, 25, 26•, 27-29]. Some studies have reported significant positive associations, but others found no associations. To summarize epidemiologic findings, we conducted a systematic review of the epidemiologic studies on the association between ambient air pollution and T2DM. We searched for studies on the incidence and 
prevalence of T2DM, diabetes mortality, and glucose homeostatic measures such as fasting glucose, insulin, homeostatic model assessment-insulin resistance (HOMA-IR), and glycosylated hemoglobin $\left(\mathrm{HbA}_{1 \mathrm{c}}\right)$. Because of small numbers of studies identified in each outcome and heterogeneity in air pollutants, we conducted a meta-analysis only for long-term exposure to fine particles $\left(\mathrm{PM}_{2.5}\right)$ and incident $\mathrm{T} 2 \mathrm{DM}$ to compute a summary measure of association. For other outcomes, we summarized each study findings descriptively.

\section{Methods}

Search Strategy and Data Extraction

We conducted a literature search in PubMed and Web of Science on 7 January 2014 using the following key words: (air pollution OR particulate matter OR $\mathrm{PM}_{10} \mathrm{OR} \mathrm{PM}_{2.5}$ OR nitrogen oxides OR nitrogen dioxide OR fine particles OR coarse particles OR ozone OR traffic particle OR traffic exhaust NOT nitric oxide) AND (type 2 diabetes OR diabetes mellitus OR insulin OR glucose). We searched publications between January 1990 and December 2013, given that epidemiologic studies of air pollution and T2DM have received attention just recently. In the Web of Science, we restricted articles from the following categories: Environmental sciences; Pharmacology pharmacy; Toxicology; Endocrinology metabolism; Public environmental occupational health; Cardiac cardiovascular system; Medicine general internal; Multidisciplinary science. A total of 933 articles from PubMed and 481 from Web of Science were identified and the abstracts were reviewed. Only human studies that included original data were considered. We also excluded studies conducted in children or pregnant women (gestational diabetes), studies with no air pollution data, studies with no effect estimate in relation to air pollution exposure, or studies that examined T2DM as an effect modifier. Finally, 21 original studies were included in this review. We extracted the following information from each study and summarized by study design: first author, year of publication, study population, sample size, study (follow-up) period, age, percent of female subjects, exposure distribution [median (interquartile range [IQR]), mean \pm standard deviation, or range], number of cases, covariates adjusted, and measures of association. We only considered exposure measures from ambient concentrations of air pollutants (i.e., studies on indoor air pollution were excluded) and did not include exposure measures from emission inventory.

\section{Statistical Analysis}

To make the reported measures of association [e.g., hazard ratio (HR), odds ratio (OR), percent change] across studies comparable, we rescaled the effect estimates for an IQR increase and for a $10-\mathrm{unit}\left(\mu \mathrm{g} / \mathrm{m}^{3}\right.$ or $\left.\mathrm{ppb}\right)$ increase. We conducted a meta-analysis of the association between $\mathrm{PM}_{2.5}$ and incident T2DM with the four cohort studies identified [13, 15, 26•]. We used a random-effects model to compute a summary HR. Two studies reported HRs from a multi-pollutant model $[15,26 \bullet]$. We extracted all reported HRs but considered the HRs from a single pollutant model in the meta-analysis. Because the number of studies for the meta-analysis was small, we did not perform a test for publication bias. $\mathrm{R}$ version 3.0.2 (R Foundation for Statistical Computing, http://www.r-project.org) with the package metafor was used.

\section{Results}

We included six prospective cohort studies on incident T2DM; two prospective cohort studies on diabetes mortality; four cross-sectional studies on the prevalence of T2DM or impaired glucose metabolism (IGM) (fasting glucose $\geq 100 \mathrm{mg} / \mathrm{dL}$ or physician-diagnosis); three studies on continuous measures of glucose homeostasis; four ecological studies on mortality from diabetes; and three ecological studies on hospital/emergency admissions for diabetes.

Long-Term Exposure to Air Pollution and Incidence of Type 2 Diabetes Mellitus (T2DM)

We identified six cohort studies of incident T2DM (Table 1) $[10,13,15,23 \cdot, 26 \cdot]$. Two independent cohort studies [the Nurses' Health Study (NHS) and the Health Professional Follow-up Study (HPFS)] were examined in a study by Puett and colleagues [26*]. Three studies were performed in the USA and one each in Germany, Denmark, and Canada. Three cohort studies [SALIA (Study on the Influence of Air Pollution on Lung, Inflammation and Aging), BWHS (Black Women's Health Study), and NHS] included only women and the HPFS included only men. Incidence rates ranged from 402 per 100,000 subjects in HPFS to 1,302 per 100,000 in the Ontario residents' study. Four studies examined either $\mathrm{PM}_{2.5}$ (annual mean ranged from 10.6 to $21.1 \mu \mathrm{g} / \mathrm{m}^{3}$ ) or $\mathrm{PM}_{10}(26.9$ to $\left.46.9 \mu \mathrm{g} / \mathrm{m}^{3}\right)$; three studies examined either nitrogen oxides $\left(\mathrm{NO}_{\mathrm{x}}\right)(41.6 \mathrm{ppb})$ or nitrogen dioxide $\left(\mathrm{NO}_{2}\right)(14.5$ to $41.7 \mu \mathrm{g} /$ $\mathrm{m}^{3}$ ). For PM, all four studies found weak positive associations and only the Ontario residents' study reported a statistically significant association [adjusted $\mathrm{HR}=1.06$ (95\% CI 1.01, 1.11) for an IQR increase in $\mathrm{PM}_{2.5}\left(5.4 \mu \mathrm{g} / \mathrm{m}^{3}\right)$; $\mathrm{HR}=1.11$ (95\% CI 1.02, 1.21) for a $10 \mu \mathrm{g} / \mathrm{m}^{3}$ increase] [13]. The random-effect summary HR for a $10 \mu \mathrm{g} / \mathrm{m}^{3}$ increase in $\mathrm{PM}_{2.5}$ was 1.11 (95\% CI 1.03, 1.19), with no evidence of heterogeneity among the three studies with $\mathrm{PM}_{2.5}$ measures 


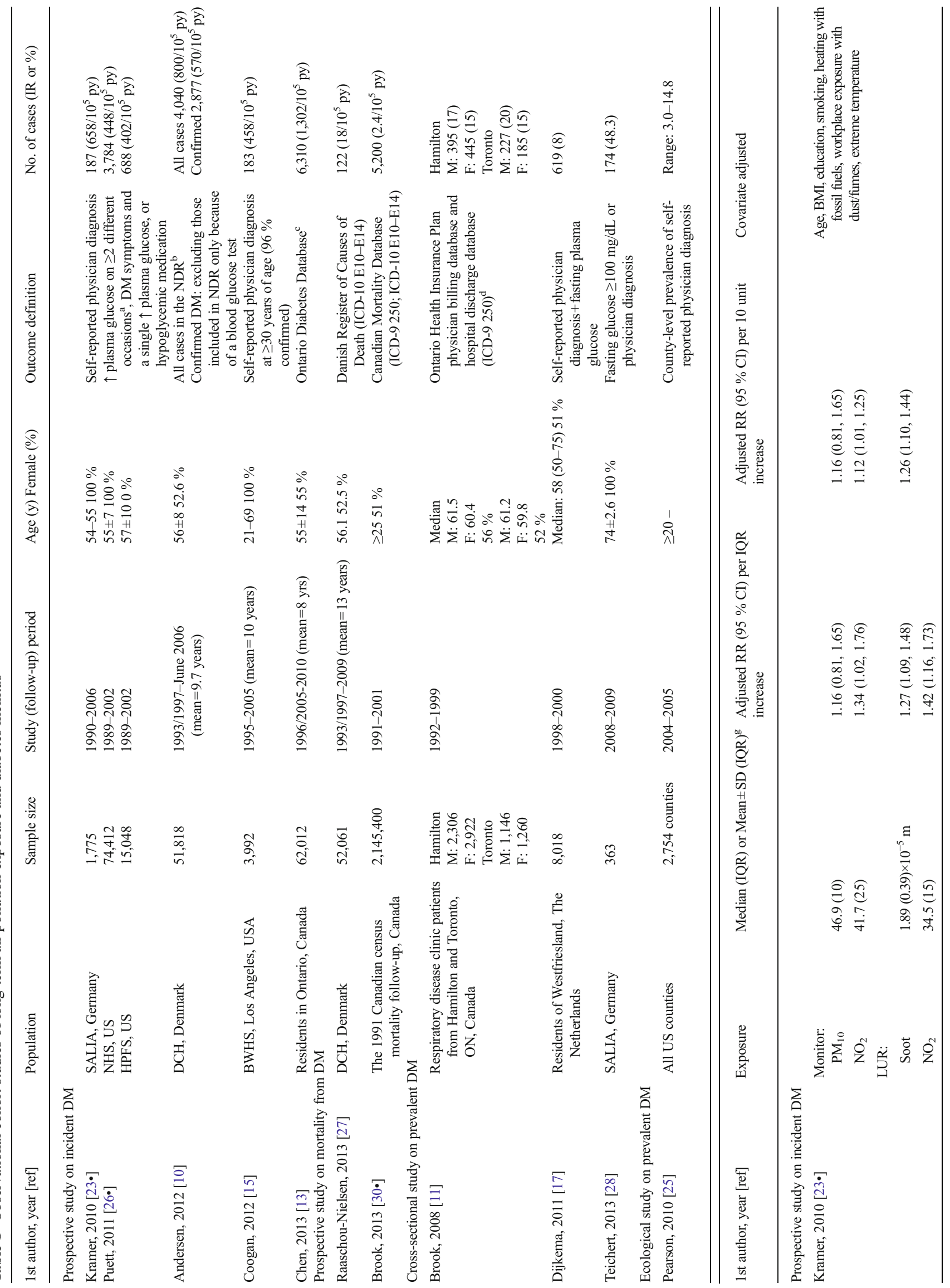




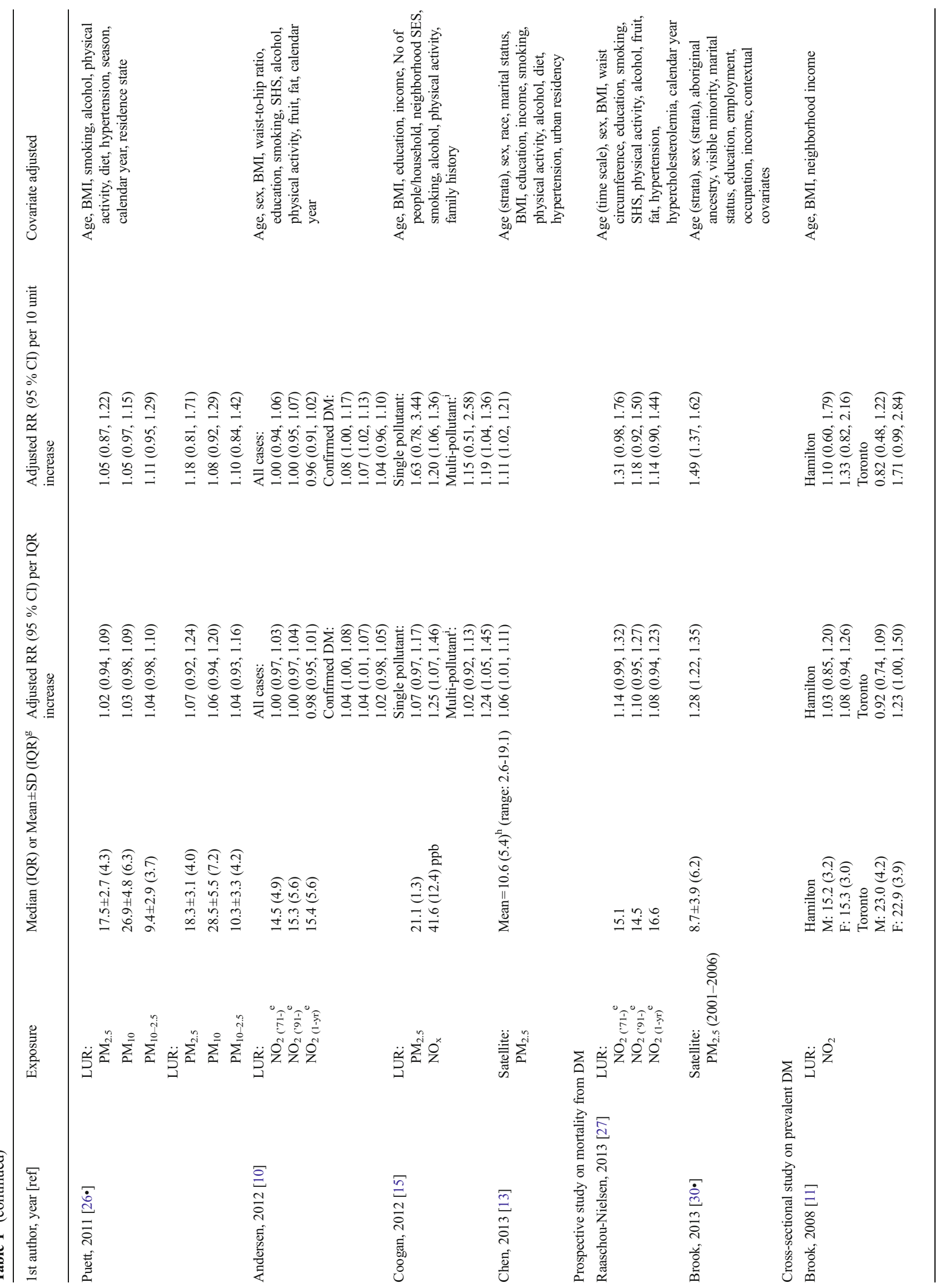




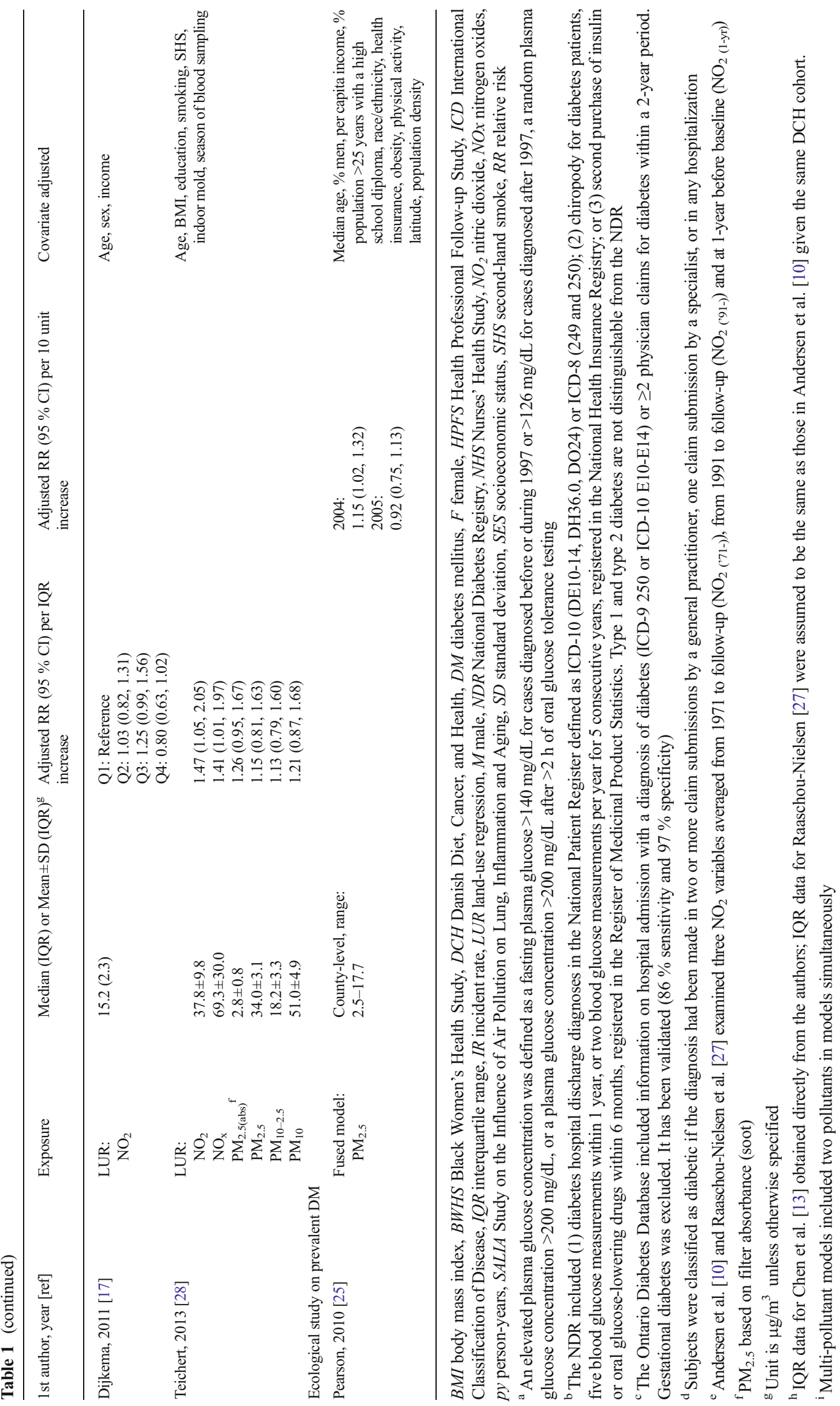


available (test for heterogeneity: $\mathrm{Q}_{\mathrm{df}=3}=1.08, p$-value $=0.78$ ) (Fig. 1). For $\mathrm{NO}_{2}$ or $\mathrm{NO}_{\mathrm{x}}$ (traffic-related particles), two studies conducted in women's cohorts reported significant positive associations $\left[\mathrm{HR}=1.42(95 \% \mathrm{CI} 1.16,1.73)\right.$ for $\mathrm{NO}_{2}(\mathrm{IQR}=$ $\left.15 \mu \mathrm{g} / \mathrm{m}^{3}\right)$ in SALIA; HR=1.25 (95\% CI 1.07, 1.46) for $\mathrm{NO}_{\mathrm{x}}$ $(\mathrm{IQR}=12.4 \mathrm{ppb})$ in $\mathrm{BWHS}]$, whereas the Danish Diet, Cancer, and Health (DCH) study found no association when all cases of T2DM were examined but found a weak marginal association when only confirmed T2DM cases were considered [HR= $1.04(95 \%$ CI $1.00,1.08)$ for $\left.\mathrm{NO}_{2}\left(\mathrm{IQR}=4.9 \mu \mathrm{g} / \mathrm{m}^{3}\right)\right]$.

Two studies examined long-term exposure to air pollution and incident diabetes mortality $[30 \bullet, 27]$. In a study conducted in Denmark (the DHC cohort study followed from 1993 to 2009, $N=52,061,122$ cases), an IQR increase in $\mathrm{NO}_{2}(\mathrm{IQR}=$ $4.9 \mu \mathrm{g} / \mathrm{m}^{3}$ ) averaged from 1971 to the follow-up period was associated with an HR for diabetes equal to 1.14 (95\% CI $0.99,1.32)[27]$. A large national follow-up study conducted in Canada (the 1991 Canadian census mortality follow-up from 1991 to 2001, $N=2,145,400,5,200$ cases) found a significant positive association between average concentrations of $\mathrm{PM}_{2.5}$ for the period from 2001 to 2006 and diabetes mortality $[\mathrm{HR}=1.28(95 \% \mathrm{CI} 1.22,1.35)$ for an IQR increase in $\left.\mathrm{PM}_{2.5}\left(6.2 \mu \mathrm{g} / \mathrm{m}^{3}\right)\right]\left[30^{\bullet}\right]$.

Long-Term Exposure to Air Pollution and Prevalence of T2DM

Four studies (three observational and one ecological) reported cross-sectional associations between long-term air pollution and prevalence of T2DM or IGM (Table 1). Two observational cross-sectional studies performed in Canada and The Netherlands examined annual $\mathrm{NO}_{2}$ concentrations as the

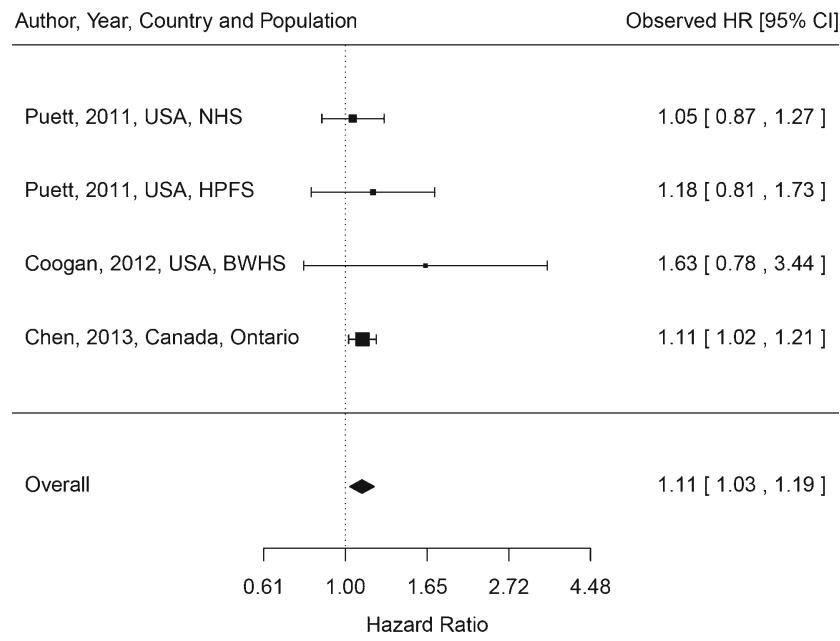

Fig. 1 Meta-analysis of the association between $\mathrm{PM}_{2.5}$ and incident diabetes. Hazard ratios were based on a $10 \mu \mathrm{g} / \mathrm{m}_{3}$ increase. A randomeffects model was used to compute the overall (summary) hazard ratio. $B W H S$ Black Women's Health Study, HPFS Health Professional Followup Study, HR hazard ratio, NHS Nurses' Health Study exposure measure, whereas the SALIA study (Germany) examined various air pollution measures including $\mathrm{PM}_{2.5}, \mathrm{PM}_{10-2.5}$, $\mathrm{PM}_{10}, \mathrm{NO}_{2}$, and $\mathrm{NO}_{\mathrm{x}}$. The ecological study conducted in the USA was based on county levels of diabetes prevalence and $\mathrm{PM}_{2.5}$ annual concentrations in 2004 and $2005(N=2,754$ counties). In patients from a respiratory disease clinic from Hamilton $(N=5,228$, prevalence of $\mathrm{T} 2 \mathrm{DM}=15 \%)$ and Toronto $(N=2,406$, prevalence of $\mathrm{T} 2 \mathrm{DM}=17 \%), \mathrm{ON}$, Canada, an IQR increase in $\mathrm{NO}_{2}$ was positively associated with T2DM among women $[\mathrm{OR}=1.08(95 \%$ CI $0.94,1.26)$ in Hamilton; OR $=1.23(95 \%$ CI 1.00, 1.50) in Toronto] but not men $[\mathrm{OR}=1.03(95 \%$ CI $0.85,1.20)$ in Hamilton; $\mathrm{OR}=0.92$ (95\% CI $0.74,1.09)$ in Toronto] [11]. In a study of 8,018 residents (prevalence of $\mathrm{T} 2 \mathrm{DM}=8 \%$ ) from Westfriesland, The Netherlands, $\mathrm{NO}_{2}$ was not associated with the prevalence of T2DM [17]. A study conducted in the SALIA cohort, Germany $(N=363,100 \%$ women, prevalence of IGM=48 \%) found significant positive associations of IGM with $\mathrm{NO}_{2}[\mathrm{OR}=1.47$ $(95 \%$ CI $1.05,2.05)$ per IQR increase $]$ and $\mathrm{NO}_{x}[\mathrm{OR}=1.41$ $(95 \%$ CI 1.01, 1.97)] [28]. Finally, in an ecological study of the association between county-level $\mathrm{PM}_{2.5}$ concentrations and diabetes prevalence in the USA [25], a $10 \mu \mathrm{g} / \mathrm{m}^{3}$ increase in $\mathrm{PM}_{2.5}$ was associated with a $1.15 \%(95 \%$ CI $1.02,1.32)$ increase in the diabetes prevalence in 2004 and a $0.92 \%$ $(95 \%$ CI $0.75,1.13)$ increase in 2005.

\section{Air Pollution and Measures of Glucose Homeostasis}

Three studies evaluated continuous measures of glucose homeostasis (Table 2) [12, 14, 21]. A study from Taiwan examined the associations of long-term exposures (annual concentrations) with five criteria pollutants $\left[\mathrm{PM}_{2.5}, \mathrm{PM}_{10}, \mathrm{NO}_{2}\right.$, sulfur dioxide $\left(\mathrm{SO}_{2}\right)$, and ozone $\left.\left(\mathrm{O}_{3}\right)\right]$, whereas two studies from Korea and Michigan, USA, examined short-term exposures (up to 7-day lags of $\mathrm{PM}_{10}, \mathrm{NO}_{2}, \mathrm{SO}_{2}$, and $\mathrm{O}_{3}$ in the Korean study; 5-day long exposure to $\mathrm{PM}_{2.5}$ in the US study). All three examined fasting glucose levels; a study from Taiwan additionally examined $\mathrm{HbA}_{1 \mathrm{c}}$, a measure of glycated hemoglobin in red blood cells that reflects the average glucose level over the previous 3 months [31]; two studies from Korea and Michigan examined fasting insulin and an indicator of insulin resistance (HOMA-IR) [12, 21]. In a study of 1,023 participants from the Social Environment and Biomarkers of Aging Study in Taiwan, fasting glucose and $\mathrm{HbA}_{1 \mathrm{c}}$ were associated with all criteria pollutants except $\mathrm{SO}_{2}$ [14]. A study of 560 older people in Korea reported that short-term exposure to $\mathrm{PM}_{10}, \mathrm{NO}_{2}$, and $\mathrm{O}_{3}$ but not $\mathrm{SO}_{2}$ were associated with increased fasting glucose, insulin and HOMA-IR, which suggests reduced metabolic insulin sensitivity [21]. A human panel study with 25 healthy non-smoking adults conducted in Michigan also found that subacute exposure to $\mathrm{PM}_{2.5}$ (5day-long cumulative exposure) was associated with increased fasting glucose, insulin, and HOMA-IR [12]. 


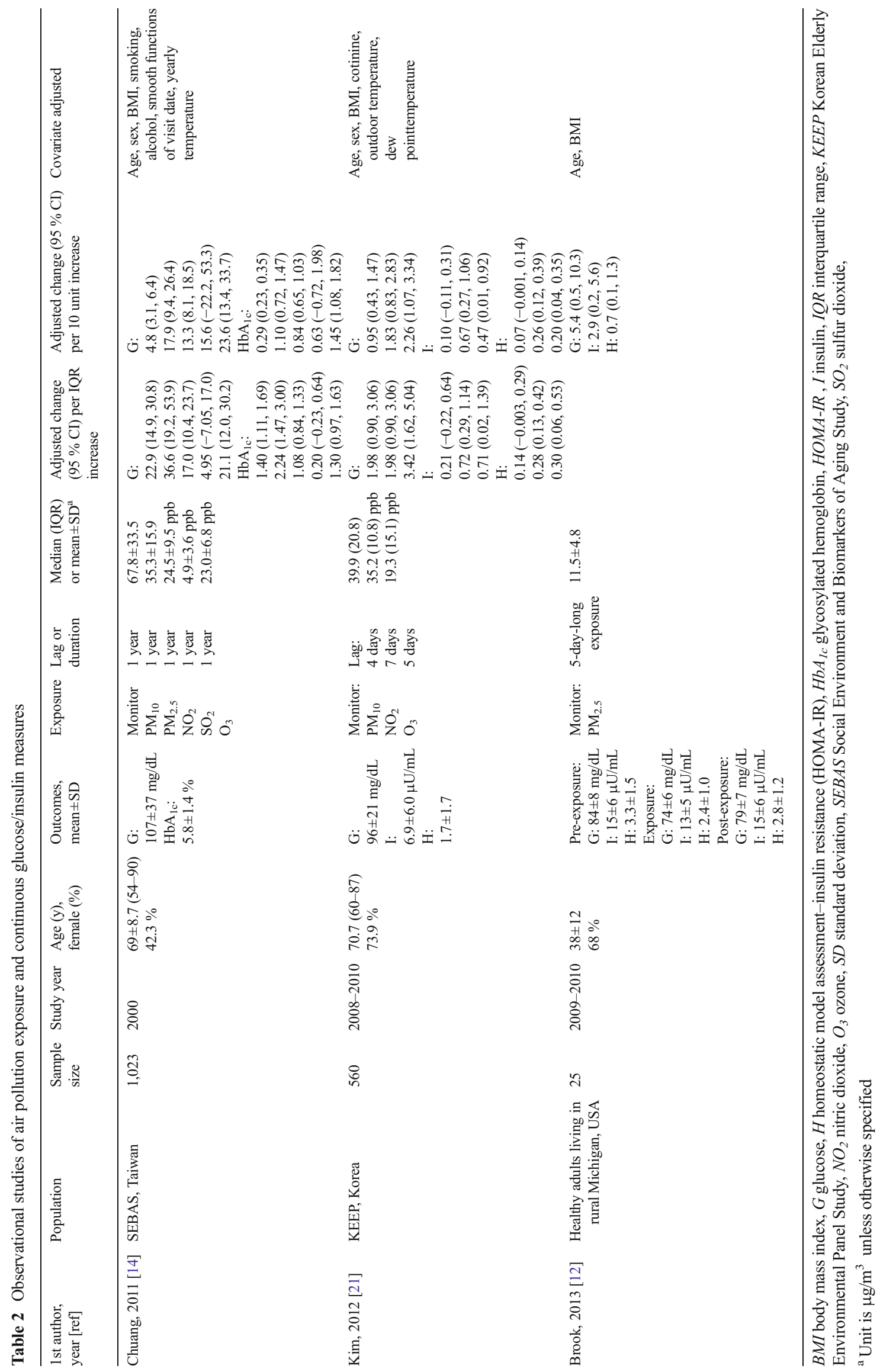




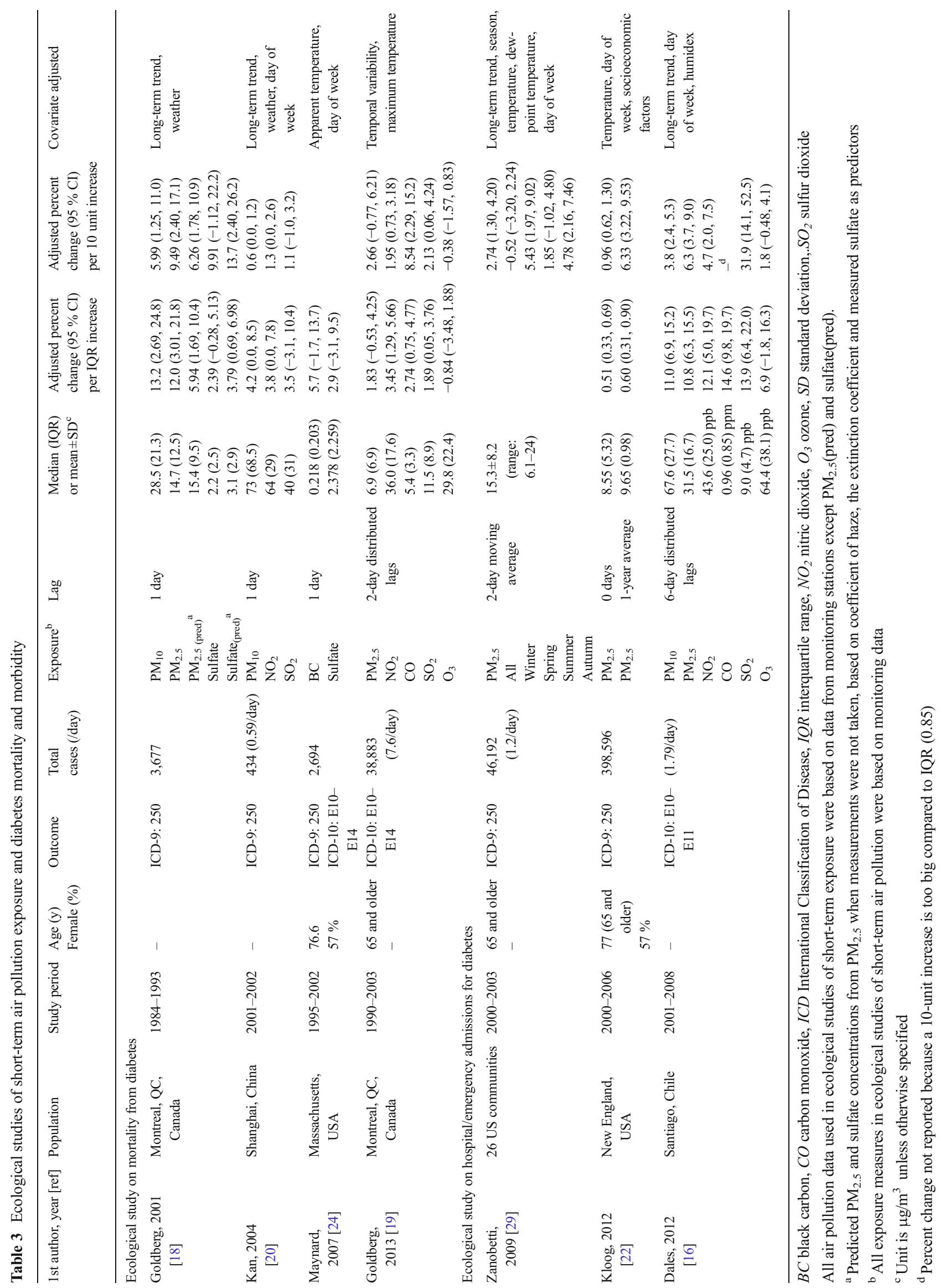


Short-Term Exposure to Air Pollution and Mortality from Diabetes

We identified four ecological studies (Poisson timeseries or case-crossover design studies) of short-term exposure to air pollution and mortality from diabetes (Table 3) $[18-20,24]$. These studies included both type 1 and type 2 diabetes. In a study conducted in Montreal, QC, Canada between 1984 and 1993, the estimated percent change in daily diabetes mortality for an IQR increase in air pollution was $13.2 \%$ (95 \% CI 2.69, 24.8) for $\mathrm{PM}_{10}, 12.0 \%(95 \%$ CI $3.01,21.8)$ for $\mathrm{PM}_{2.5}$, and $3.79 \%(95 \%$ CI 0.69 , 6.98) for sulfate (predicted from $\mathrm{PM}_{2.5}$ ). In a later study conducted between 1990 and 2003, the corresponding percent changes were $3.45 \%(95 \%$ CI $1.29,5.66)$ for $\mathrm{NO}_{2}, 2.74 \%(95 \%$ CI $0.75,4.77)$ for carbon monoxide (CO), and $1.89 \%(95 \% \mathrm{CI} 0.05,3.76)$ for $\mathrm{SO}_{2}$ [19]. A time-series study using daily mortality from diabetes between 2001 and 2002 conducted in Shanghai, China observed marginal associations with $\mathrm{PM}_{10}$ [4.18\% $(95 \%$ CI $0.00,8.54)$ per IQR increase] and $\mathrm{SO}_{2}$ [3.82\% (95\% CI 0.00, 7.78)] [20]. In Massachusetts, black carbon $[5.7 \%(95 \% \mathrm{CI}-1.7,13.7)]$ and sulfate $[2.9 \%(95 \% \mathrm{CI}-3.1,9.5)]$ were positively but nonsignificantly associated with the deaths from diabetes for the years 1995-2002 [24].

\section{Short-Term Exposure to Air Pollution}

and Hospital/Emergency Admissions for Diabetes

Three studies examined hospital/emergency admissions for diabetes using the time-series Poisson model analysis or the case-crossover design (Table 3) [16, 22, 29]. These studies also included both type 1 and type 2 diabetes. Two studies by Zanobetti et al. [29] and Dales et al. [16] examined short-term exposures to air pollution, and one study by Kloog et al. [22] examined both short-term and long-term effects of $\mathrm{PM}_{2.5}$. Zanobetti et al. found that a $10 \mu \mathrm{g} / \mathrm{m}^{3}$ increase in 2day averaged $\mathrm{PM}_{2.5}$ was associated with a $2.74 \%$ (95\% CI 1.30, 4.20) increase in emergency admissions for diabetes in 26 US communities between 2000 and 2003 [29]. In a study from Santiago, Chile between 2001 and 2008, Dales et al. found that IQR increases in criteria pollutants except $\mathrm{O}_{3}$ were associated with an $11 \%$ to a $15 \%$ increase in the risk for hospitalization for diabetes [16]. In a study conducted in New England, USA, a $10 \mu \mathrm{g} / \mathrm{m}^{3}$ increase in short-term and long-term $\mathrm{PM}_{2.5}$ was associated with a $0.96 \%$ (95\% CI 0.62 , $1.30)$ and a $6.33 \%(95 \%$ CI $3.22,9.53)$ increase in the risk for diabetes hospitalization, respectively [22].

\section{Discussion}

In general, two different study designs were used to examine the association between air pollution and T2DM: observational studies of incidence, prevalence, or mortality from T2DM or continuous measures of insulin resistance in relation to long-term exposure to air pollution; and ecological studies of daily mortality or hospital/emergency admissions in relation to short-term exposure. For the incidence and prevalence studies and observational diabetes mortality studies, either annual concentrations of particulate matters [mostly $\mathrm{PM}_{2.5}$ or $\mathrm{PM}_{10}$ and $\mathrm{PM}_{10-2.5}$ (coarse particles)] or nitrogen oxides $\left(\mathrm{NO}_{\mathrm{x}}\right.$ or $\left.\mathrm{NO}_{2}\right)$, which were estimated using land-use regression $\left[10,11,15,17,26 \bullet, 27,28,30^{\bullet}\right]$ or a satellite-based approach [13], were used as exposure metrics, whereas ecological studies of diabetes mortality or hospital/emergency admissions (except the study by Kloog et al. [22]) used daily concentrations of criteria pollutants $\left(\mathrm{PM}_{2.5}, \mathrm{PM}_{10}, \mathrm{NO}_{2}, \mathrm{CO}\right.$, $\mathrm{SO}_{2}$, and $\mathrm{O}_{3}$ ) based on central monitoring or the nearest monitors. Given the differences in study design and disease etiology between long-term air pollution effects on the development of T2DM versus short-term air pollution effects on daily diabetes mortality or morbidity, we discussed causal relationships based on epidemiologic findings by these two study designs separately.

\section{Observational Studies in Relation to Long-Term Exposure}

Consistency For $\mathrm{PM}_{2.5}$, all studies showed positive associations with either incident T2DM [13, 15, 23•, 26•], diabetes mortality [30•], or prevalent IGM [28]. Our meta-analysis suggests an association between $\mathrm{PM}_{2.5}$ and incident $\mathrm{T} 2 \mathrm{DM}$ with a small summary HR of $1.11(95 \%$ CI 1.03, 1.19). One large national-level study that examined more than 2 million Canadians showed a strong positive association between $\mathrm{PM}_{2.5}$ and diabetes mortality. For $\mathrm{NO}_{2}$ or $\mathrm{NO}_{\mathrm{x}}$, a measure of traffic particle exposure, three studies from two women's cohorts (SALIA and BWHS) reported a significant association with incident T2DM [15, 23•] or prevalent IGM [28], and one relatively large study from Denmark (approximately 52,000 participants) also reported a significant association with confirmed T2DM (but not with all cases of T2DM) [10] or diabetes mortality [27]. Two other cross-sectional studies also found a suggestive association with prevalent T2DM only among women $[11,17]$.

Strength One Canadian census mortality study and two women's cohort studies (SALIA and BWHS) reported relatively strong associations (HRs from 1.25 to 1.42 for an IQR increase in $\mathrm{PM}_{2.5}, \mathrm{NO}_{\mathrm{x}}$, or $\mathrm{NO}_{2}$ ), whereas other studies reported modest associations (i.e., HRs or ORs $<1.1$ ). Although most studies used land-use regression models to generate improved exposure estimates, the use of stationary monitoring 
data rather than personal monitoring may lead to exposure measurement error. Another potential source of exposure measurement error is that 1-year average concentrations prior to baseline or at any given year are used as proxies for the long-term exposure. Exposure measurement error may occur if individual exposure levels have changed over time before baseline, e.g., if individuals have moved often before baseline. These errors generally bias the observed association towards the null.

Temporality Eight prospective studies have examined incident T2DM or diabetes mortality, which supports the temporality issue that the cause precedes the effect in time. Reverse causation is unlikely given that onset of T2DM may not lead to an increase in air pollution exposure.

Biological Plausibility As introduced earlier, several animal studies support potential biological mechanisms, e.g., cumulative exposure to air pollution can lead to a reduction in Akt phosphorylation in the liver, skeletal muscle, and white adipose tissue, which influences the insulin signaling pathway and apoptosis [32, 33]. Fine particulate matter exposure can induce inflammation in visceral adipose tissue by increasing adipose tissue macrophages [34]. $\mathrm{PM}_{2.5}$ exposure may also induce ER stress not only in the lung but in the liver, which induces hepatic insulin resistance [35]. These mechanisms eventually affect insulin resistance and cause T2DM $[8,9 \bullet]$.

Causal Inference Based on consistency of the observed findings, the evidence of the association between long-term exposure to $\mathrm{PM}_{2.5}$ and the risk of T2DM is suggestive. The vast majority of studies were conducted in North America or Europe and little evidence was reported from other areas. The evidence on the association between long-term trafficrelated exposure (measured by nitrogen dioxide or nitrogen oxides) and the risk of T2DM is also suggestive, although most studies were conducted in women. The fact that two primary studies showing significant associations between traffic exposure and incident T2DM were conducted in women's cohorts and most other studies have reported a significant association only among women suggests that women may be more susceptible to an air pollution-related response to T2DM. It is unclear whether the stronger associations in women are consequences of sex-related biological differences or gender-related behavioral or social differences [36], which needs further investigation.

\section{Ecological Studies in Relation to Short-Term Exposure}

Consistency and Strength For mortality from T2DM, three studies examined either $\mathrm{PM}_{10}$ or $\mathrm{PM}_{2.5}$ : a time-series study from Shanghai, China found a marginal association [20]. In studies performed in Montreal, Canada, the earlier study that examined mortality between 1984 and 1993 in which the median concentrations of $\mathrm{PM}_{2.5}$ and $\mathrm{PM}_{10}$ were 28.5 and $14.7 \mu \mathrm{g} / \mathrm{m}^{3}$ reported a significant association (12 and $13 \%$ increases in diabetes mortality per IQR increase in $\mathrm{PM}_{2.5}$ and $\mathrm{PM}_{10}$, respectively) [18], whereas a more recent study that examined mortality between 1990 and 2003 in which the median $\mathrm{PM}_{2.5}$ concentration was $6.9 \mu \mathrm{g} / \mathrm{m}^{3}$ found no association [19]. For hospital/emergency admissions, all three studies reported significant associations with $\mathrm{PM}_{2.5}$. Two US studies where $\mathrm{PM}_{2.5}$ concentrations were 9 to $15 \mu \mathrm{g} / \mathrm{m}^{3}$ reported weak positive associations ( 0.96 and $2.74 \%$ per $10 \mu \mathrm{g} /$ $\mathrm{m}^{3}$ increase in $\mathrm{PM}_{2.5}$ ), whereas a time-series study performed in Santiago, Chile where $\mathrm{PM}_{2.5}$ concentrations were twofold higher (median $\mathrm{PM}_{2.5}=31.5 \mu \mathrm{g} / \mathrm{m}^{3}$ ) found a $6 \%$ increased risk per $10 \mu \mathrm{g} / \mathrm{m}^{3}$ increase in $\mathrm{PM}_{2.5}$.

Biological Plausibility For short-term exposure, it is unclear if mortality from diabetes or hospital/emergency admissions related to diabetes were due to diabetes-related complications by dysfunctions of serum glucose control or due to acute exacerbation of other pre-existing diseases [16]. Short-term exposure to particulate matters or $\mathrm{O}_{3}$ is known to induce oxidative stress, systemic inflammation, endothelial dysfunction, and cardiac autonomic nervous system dysfunction [37], which may lead to insulin dysregulation [38, 39]. A human panel study conducted in Michigan, USA found that subacute exposure to $\mathrm{PM}_{2.5}$ was associated with reduced metabolic insulin sensitivity as measured by increased HOMA-IR and reduced heart rate variability [12], which supports the plausibility that air pollution, not only long-term but relatively short-term exposure, could influence insulin and glucose homeostasis.

Temporality The temporality issue in ecological time-series studies has been assured by examining the lagged effects [40]. Nonetheless, most studies explored only short laggedexposure periods, such as a 0 or 1-day lag or a 2-day distributed lag because many previous studies of total and cardiovascular mortality and morbidity reported larger associations with particle exposures at 0 to 2 -day lags. Whether short-term air pollution exposure has immediate effects on glucose and insulin functions or more delayed effects remains to be explored in the future.

Causal Inference We conclude that the evidence is not sufficient to infer a causal relationship of short-term exposure to air pollution and mortality or hospital/ emergency admissions for diabetes. Although a few studies suggest potential mechanisms, those are not specific to glucose and insulin actions and direct mechanisms are unknown. Most previous studies examined diabetes mortality and morbidity along with cardiovascular and respiratory outcomes. 


\section{Conclusion}

Our systematic review suggests that the evidence is suggestive to infer a causal relationship between fine-particle exposure and the risk of T2DM and there is suggestive evidence of an association between traffic-related exposure and incident T2DM, especially in women. Because most studies were conducted in North America or in Europe where exposure levels are relatively low, more studies are needed in recently urbanized areas in Asia and Latin America where air pollution levels are much higher and T2DM is an emerging public health concern $[41,42]$ to increase the power and to determine the dose-response relationships.

Acknowledgments Sung Kyun Park was supported by the National Institute of Environmental Health Sciences (NIEHS) K01-ES016587. Additional support was provided by NIEHS Grant P30-ES017885 entitled "Lifestage Exposure and Adult Disease".

\section{Compliance with Ethics Guidelines}

Conflict of Interest Sung Kyun Park and Weiye Wang declare that they have no conflict of interest.

Human and Animal Rights and Informed Consent This article does not contain any studies with human or animal subjects performed by any of the authors.

\section{References}

Papers of particular interest, published recently, have been highlighted as:

- Of importance

1. American Diabetes Association. Standards of medical care in diabetes-2013. Diabetes Care. 2013;36 Suppl 1:S11-66.

2. Danaei G, Finucane MM, Lu Y, Singh GM, Cowan MJ, Paciorek $\mathrm{CJ}$, et al. National, regional, and global trends in fasting plasma glucose and diabetes prevalence since 1980: systematic analysis of health examination surveys and epidemiological studies with 370 country-years and 2.7 million participants. Lancet. 2011;378(9785):31-40.

3. Lim SS, Vos T, Flaxman AD, Danaei G, Shibuya K, Adair-Rohani $\mathrm{H}$, et al. A comparative risk assessment of burden of disease and injury attributable to 67 risk factors and risk factor clusters in 21 regions, 1990-2010: a systematic analysis for the Global Burden of Disease Study 2010. Lancet. 2012;380(9859):2224-60.

4. Morris AP, Voight BF, Teslovich TM, Ferreira T, Segre AV, Steinthorsdottir V, et al. Large-scale association analysis provides insights into the genetic architecture and pathophysiology of type 2 diabetes. Nat Genet. 2012;44(9):981-90.

5. Voight BF, Scott LJ, Steinthorsdottir V, Morris AP, Dina C, Welch $\mathrm{RP}$, et al. Twelve type 2 diabetes susceptibility loci identified through large-scale association analysis. Nat Genet. 2010;42(7): 579-89.
6. Willett WC. Balancing life-style and genomics research for disease prevention. Science. 2002;296(5568):695-8.

7. Thayer KA, Heindel JJ, Bucher JR, Gallo MA. Role of environmental chemicals in diabetes and obesity: a National Toxicology Program workshop review. Environ Health Perspect. 2012;120(6):779-89.

8. Liu C, Ying Z, Harkema J, Sun Q, Rajagopalan S. Epidemiological and Experimental Links between Air Pollution and Type 2 Diabetes. Toxicol Pathol. 2012;41(2):361-73.

9. Rajagopalan S, Brook RD. Air pollution and type 2 diabetes: mechanistic insights. Diabetes. 2012;61(12):3037-45. This review article demonstrates potential biological mechanisms based on previous experimental studies.

10. Andersen ZJ, Raaschou-Nielsen O, Ketzel M, Jensen SS, Hvidberg $\mathrm{M}$, Loft S, et al. Diabetes incidence and long-term exposure to air pollution: a cohort study. Diabetes Care. 2012;35(1):92-8.

11. Brook RD, Jerrett M, Brook JR, Bard RL, Finkelstein MM. The relationship between diabetes mellitus and traffic-related air pollution. J Occup Environ Med. 2008;50(1):32-8.

12. Brook RD, Xu X, Bard RL, Dvonch JT, Morishita M, Kaciroti N, et al. Reduced metabolic insulin sensitivity following sub-acute exposures to low levels of ambient fine particulate matter air pollution. Sci Total Environ. 2013;448:66-71.

13. Chen H, Burnett RT, Kwong JC, Villeneuve PJ, Goldberg MS, Brook RD, et al. Risk of incident diabetes in relation to long-term exposure to fine particulate matter in Ontario, Canada. Environ Health Perspect. 2013;121(7):804-10.

14. Chuang KJ, Yan YH, Chiu SY, Cheng TJ. Long-term air pollution exposure and risk factors for cardiovascular diseases among the elderly in Taiwan. Occup Environ Med. 2011;68(1):64-8.

15. Coogan PF, White LF, Jerrett M, Brook RD, Su JG, Seto E, et al. Air pollution and incidence of hypertension and diabetes mellitus in black women living in Los Angeles. Circulation. 2012;125(6):767-72.

16. Dales RE, Cakmak S, Vidal CB, Rubio MA. Air pollution and hospitalization for acute complications of diabetes in Chile. Environ Int. 2012;46:1-5.

17. Dijkema MB, Mallant SF, Gehring U, van den Hurk K, Alssema M, van Strien RT, et al. Long-term exposure to traffic-related air pollution and type 2 diabetes prevalence in a cross-sectional screening-study in the Netherlands. Environ Health. 2011;10:76.

18. Goldberg MS, Burnett RT, Bailar 3rd JC, Brook J, Bonvalot Y, Tamblyn R, et al. The association between daily mortality and ambient air particle pollution in Montreal, Quebec. 2. Causespecific mortality. Environ Res. 2001;86(1):26-36.

19. Goldberg MS, Burnett RT, Stieb DM, Brophy JM, Daskalopoulou SS, Valois MF, et al. Associations between ambient air pollution and daily mortality among elderly persons in Montreal. Quebec Sci Total Environ. 2013;463-464:931-42.

20. Kan H, Jia J, Chen B. The association of daily diabetes mortality and outdoor air pollution in Shanghai. China J Environ Health. 2004;67(3):21-6.

21. Kim JH, Hong YC. GSTM1, GSTT1, and GSTP1 polymorphisms and associations between air pollutants and markers of insulin resistance in elderly Koreans. Environ Health Perspect. 2012;120(10):1378-84.

22. Kloog I, Coull BA, Zanobetti A, Koutrakis P, Schwartz JD. Acute and chronic effects of particles on hospital admissions in NewEngland. PLoS One. 2012;7(4):e34664.

23. Kramer U, Herder C, Sugiri D, Strassburger K, Schikowski T, Ranft $\mathrm{U}$, et al. Traffic-related air pollution and incident type 2 diabetes: results from the SALIA cohort study. Environ Health Perspect. 2010;118(9):1273-9. This is the first epidemiologic study that examined long-term air pollution exposure and incident type 2 diabetes and reported a significant association.

24. Maynard D, Coull BA, Gryparis A, Schwartz J. Mortality risk associated with short-term exposure to traffic particles and sulfates. Environ Health Perspect. 2007;115(5):751-5. 
25. Pearson JF, Bachireddy C, Shyamprasad S, Goldfine AB, Brownstein JS. Association between fine particulate matter and diabetes prevalence in the U.S. Diabetes Care. 2010;33(10): 2196-201.

26. Puett RC, Hart JE, Schwartz J, Hu FB, Liese AD, Laden F. Are particulate matter exposures associated with risk of type 2 diabetes? Environ Health Perspect. 2011;119(3):384-9. This study was conducted in two large prospective cohort studies, the Nurses' Health Study and the Health Professional Follow-up Study, with a longterm follow-up.

27. Raaschou-Nielsen O, Sorensen M, Ketzel M, Hertel O, Loft S, Tjonneland A, et al. Long-term exposure to traffic-related air pollution and diabetes-associated mortality: a cohort study. Diabetologia. 2013;56(1):36-46.

28. Teichert T, Vossoughi M, Vierkotter A, Sugiri D, Schikowski T, Schulte T, et al. Association between Traffic-Related Air Pollution, Subclinical Inflammation and Impaired Glucose Metabolism: Results from the SALIA Study. PLoS One. 2013;8(12):e83042.

29. Zanobetti A, Franklin M, Koutrakis P, Schwartz J. Fine particulate air pollution and its components in association with cause-specific emergency admissions. Environ Health. 2009;8:58.

30. Brook RD, Cakmak S, Turner MC, Brook JR, Crouse DL, Peters PA, et al. Long-term fine particulate matter exposure and mortality from diabetes in Canada. Diabetes Care. 2013;36(10):3313-20. This is the largest study (more than 2 million subjects) conducted using the Canadian census mortality follow-up data, and reported a significant association.

31. Committee IE. International Expert Committee report on the role of the $\mathrm{A} 1 \mathrm{C}$ assay in the diagnosis of diabetes. Diabetes Care. 2009;32(7):1327-34.

32. Xu X, Liu C, Xu Z, Tzan K, Zhong M, Wang A, et al. Long-term exposure to ambient fine particulate pollution induces insulin resistance and mitochondrial alteration in adipose tissue. Toxicol Sci. 2011;124(1):88-98.
33. Xu Z, Xu X, Zhong M, Hotchkiss IP, Lewandowski RP, Wagner JG, et al. Ambient particulate air pollution induces oxidative stress and alterations of mitochondria and gene expression in brown and white adipose tissues. Part Fibre Toxicol. 2011;8:20.

34. Sun Q, Yue P, Deiuliis JA, Lumeng CN, Kampfrath T, Mikolaj MB, et al. Ambient air pollution exaggerates adipose inflammation and insulin resistance in a mouse model of diet-induced obesity. Circulation. 2009;119(4):538-46.

35. Laing S, Wang G, Briazova T, Zhang C, Wang A, Zheng Z, et al. Airborne particulate matter selectively activates endoplasmic reticulum stress response in the lung and liver tissues. Am J Physiol Cell Physiol. 2010;299(4):C736-49.

36. Clougherty JE. A growing role for gender analysis in air pollution epidemiology. Environ Health Perspect. 2010;118(2):167-76.

37. Brook RD, Rajagopalan S, Pope 3rd CA, Brook JR, Bhatnagar A, Diez-Roux AV, et al. Particulate matter air pollution and cardiovascular disease: An update to the scientific statement from the American Heart Association. Circulation. 2010;121(21):2331-78.

38. Carnethon MR, Golden SH, Folsom AR, Haskell W, Liao D. Prospective investigation of autonomic nervous system function and the development of type 2 diabetes: the Atherosclerosis Risk In Communities study, 1987-1998. Circulation. 2003;107(17): 2190-5.

39. Meigs JB, Hu FB, Rifai N, Manson JE. Biomarkers of endothelial dysfunction and risk of type 2 diabetes mellitus. JAMA. 2004;291(16):1978-86.

40. Campbell MJ, Tobias A. Causality and temporality in the study of short-term effects of air pollution on health. Int $\mathrm{J}$ Epidemiol. 2000;29(2):271-3.

41. Green J, Sanchez S. Air Quality in Latin America: An Overview. Washington: The Clean Air Institute; 2013.

42. Raquel AS, West JJ, Yuqiang Z, Susan CA, Jean-François L, Drew TS, et al. Global premature mortality due to anthropogenic outdoor air pollution and the contribution of past climate change. Environ Res Lett. 2013;8(3):034005. 